\title{
Utilization of health facilities and predictors of health-seeking behavior for under-five children with acute diarrhea in slums of Addis Ababa, Ethiopia: a community-based cross-sectional study
}

\author{
Metadel Adane ${ }^{1 *}$, Bezatu Mengistie ${ }^{2}$, Worku Mulat ${ }^{3}$, Helmut Kloos $^{4}$ and Girmay Medhin ${ }^{5}$
}

\begin{abstract}
Background: Information on health-seeking behavior and utilization of health facilities in slums of Addis Ababa is scarce, impeding the implementation of effective interventions. The purpose of this study is to assess the status of health facilities utilization and predictors for health-seeking behavior of mothers/caregivers of under-five children with acute diarrhea in slums of Addis Ababa, Ethiopia.

Methods: A community-based cross-sectional study design was employed in five rounds of surveys in seven kebeles in slums of Addis Ababa among 472 mothers/caregivers of 472 under-five children with acute diarrhea in reference to Andersen's behavioral model. Data were entered into EpiData Version 3.1 and analyzed using STATA Version 14.0. Descriptive statistics were used to examine patterns of health facilities utilization and multivariable logistic regression analysis was applied to identify predictors associated with health-seeking behavior.

Results: Most mothers/caregivers (70.8\%) sought care either at home (14.2\%) or health facilities (56.6\%), whereas 29.2\% reported that they did not seek any care. Of those who consulted health facilities, government health facilities (76.9\%) were more utilized than private (18.0\%) and informal (5.1\%) health facilities. Nearly all (93.9\%) of the mothers/caregivers using government health facilities used health centers, and of those who took their children to private health facilities (60.9\%) used clinics and $26.1 \%$ used pharmacies/drug vendors. Mothers/caregivers visiting health facilities obtained mainly oral rehydration salt (ORS) (39.8\%) and home-recommended fluids (HRF) (40.3\%), but few of them (11.9\%) obtained ORS plus zinc supplementation. Predisposing factors of literacy of mothers/caregivers (adjusted odds ratio (AOR) $=2.4 ; 95 \% \mathrm{Cl} 1.4-4$. 1) and occupation ( $\mathrm{AOR}=2.6 ; 95 \% \mathrm{Cl} 1.5-4.6)$, the enabling factors of households monthly income of 50 United States Dollars (US\$) and above (AOR $=2.9 ; 95 \% \mathrm{Cl} 1.5-5.6)$ and availability of nearest health facilities within 15 min walking distance (AOR $=3.3 ; 95 \% \mathrm{Cl} 1.7-6.6)$, and the need factors of recognizing danger signs of fever ( $\mathrm{AOR}=4.3 ; 95 \% \mathrm{Cl}$ 2.4-7.6) and vomiting ( $A O R=3.3 ; 95 \% \mathrm{Cl} 1.8-5.9$ ) were significantly associated with health-seeking behavior.
\end{abstract}

Conclusions: Increasing the proximity of health facilities in slums and health education and socioeconomic development programs targeting illiterate mothers/caregivers and poor households may promote and increase health-seeking behavior and the accessibility of health facilities for the treatment of acute diarrhea in under-five children in Addis Ababa slums.

Keywords: Andersen behavioral model, Enabling factor, Health-seeking behavior, Health facilities, Mothers/caregivers, Need factor, Predisposing factor, Under-five children

\footnotetext{
* Correspondence: metadel.adane2@gmail.com

'Ethiopian Institute of Water Resources (EIWR), Addis Ababa University, Addis

Ababa, Ethiopia

Full list of author information is available at the end of the article
}

\section{Ciomed Central}

(c) The Author(s). 2017 Open Access This article is distributed under the terms of the Creative Commons Attribution 4.0 International License (http://creativecommons.org/licenses/by/4.0/), which permits unrestricted use, distribution, and reproduction in any medium, provided you give appropriate credit to the original author(s) and the source, provide a link to the Creative Commons license, and indicate if changes were made. The Creative Commons Public Domain Dedication waiver (http://creativecommons.org/publicdomain/zero/1.0/) applies to the data made available in this article, unless otherwise stated. 


\section{Background}

Sub-Saharan Africa has made the least progress in the reduction of infant and child mortality [1]. The two leading causes of mortality among children under-five years of age in sub-Saharan Africa are pneumonia and diarrhea, accounting for $18 \%$ and $15 \%$, respectively [2]. Appropriate health-seeking behavior can reduce child morbidity and mortality due to diarrhea [3] and is vital for integrated management of childhood illness $[4,5]$ and child survival [6]. Based on Andersen's behavioral model, predisposing, enabling, and need factors at the individual and community levels are instrumental for increasing health-seeking behavior and health facilities utilization [7-9]. Individual and community level factors also determine the occurrence and outcome of diarrhea $[8,10]$.

Most studies using Andersen's behavioral model used secondary data with different categorizations of variables, indicating that primary studies are needed to identify predictors of health-seeking behavior [11]. Studies from various countries suggest that healthseeking behavior for childhood illnesses is often inappropriate and health facilities are under-utilized, particularly by the poor [12-16]. The 2011 citywide Demographic Health Survey in Addis Ababa indicated that less than half $(47.2 \%)$ of mothers/caregivers sought treatment for diarrhea at health facilities [17]. An understanding of health-seeking behavior is vital for the rational planning and evaluation of health services. However, in Ethiopia's urban, including slums of Addis Ababa, there is limited information on health facility utilization and predictors for health-seeking behavior for under-five children with acute diarrhea. In the current study, we adapted the Andersen behavioral model [9] as a conceptual framework to identify predictors needed to operationalize the need, predisposing, and enabling factors for enhancing health-seeking behavior for under-five children with acute diarrhea in slums of Addis Ababa.

The results may assist health policy makers, planners, non-governmental organizations, and other bodies interested in reducing child mortality and morbidity through promoting health-seeking in health facilities in slums of Addis Ababa and Ethiopia's other urban slums.

\section{Methods}

\section{Study setting}

The study was conducted in slum areas of Addis Ababa, the capital city of Ethiopia. Four slum kebeles in Gullele Sub-City's District (Woreda) 01 and three slum kebeles in Lideta Sub-City's District 05 were included in the study. There is one governmental health center in District 01, in Gullele Sub-City, but none in District 05 in Lideta Sub-City. Thus, residents of District 05 have to be served by other District health facilities.

Addis Ababa's population was projected to be 3.27 million in $2014 / 2015,47.4 \%$ of them males and $52.6 \%$ females [18]. According to the 2015 report by the District administration, there were 1453 legally registered underfive children in District 01, in Gullele Sub-City, and 1321 in District 05 in Lideta Sub-City. Ethiopia has both public and private sector health facilities. Private sector health facilities (clinics, hospitals, pharmacies, and/or drug vendors) provide mainly curative services, whereas public sector health facilities provide both curative and all preventive services. A considerable number of traditional healers also continue to operate in the informal health facility sector [19].

\section{Study design, period, and populations}

Five rounds of a community-based cross-sectional survey (one round during a case-control study and four rounds when a longitudinal study conducted) within periods of October 2014 (first round), November to December 2014 (second round), January 2015 (third round), April 2015 (fourth round), and July 2015 (fifth round) was employed. The source populations were all under-five children who had acute diarrhea during the study period in slums of Addis Ababa, whereas the study populations were under-five children with acute diarrhea that lived in the seven slum kebeles during the survey period whose mothers/caregivers consented to their participation in the study.

\section{Sample size calculation}

For sample size estimation, we assumed a 95\% confidence interval (CI), a margin of error of 5\%, a proportion of $47.2 \%$ for health-seeking in one or more health facilities in Addis Ababa [17], and a design effect of 1.5. We used design effect since the multistage sampling method was employed. A minimum adequate sample size was calculated based on the statistical estimation method of Kelsey et al. [20]. Since the source population was estimated less than 10,000; sample size correction was performed. Then, $10 \%$ non-response rate was added to obtain the adequate sample size of 429 . To satisfy the minimum adequate sample size criteria, the study included all 472 under-five children with acute diarrhea during the five rounds of survey period based on the inclusion and exclusion criteria.

\section{Inclusion and exclusion criteria}

If the same under-five children had more than one episode, we only considered the first acute diarrheal case and excluded the repeated case for the study. 
When the same mother/caregiver had another child with diarrhea, it was excluded for the study if that child was not part of the longitudinal follow-up study because we used systematic sampling technique from the initial recruitment of children for the follow-up study. During the case-control study, when there was more than one child with acute diarrhea per household, we randomly choose one of the children before interviewing the mother/caregiver. Under-five children with bloody and persistent diarrhea were also excluded.

\section{Operational definitions}

Health-seeking behavior was defined as diarrheal management practices by mothers/caregivers of under-five children with acute diarrhea for the treatment and recovery of the child from acute diarrhea within 2 weeks prior to data collection. Acute diarrhea was identified using World Health Organization (WHO) signs and symptoms for diarrhea by questioning the mothers/ caregivers first about signs and symptoms of diarrhea such as consistency of bowel movements, fever, vomiting, blood in stool, mucus in stool, watery stool, and the frequency of abnormal stool 2 weeks prior to data enumeration. We defined acute diarrhea following the WHO protocol [21] as the passage of three or more abnormally loose watery or liquid stools over a $24 \mathrm{~h}$ period. However, the WHO protocol did not specify the recall period. We used the 2 week recall period as specified in World Gastroenterology Organization global guidelines for acute diarrhea survey [22]. We therefore define acute diarrhea as the passage of three or more abnormally loose watery or liquid stools over a $24 \mathrm{~h}$ period within 2 weeks prior to the data collection.

\section{Explanatory variables}

We selected explanatory variables based on Andersen's behavioral model [9] (Fig. 1), which is widely accepted and used to study the predictors of health-seeking behavior and health facility utilization for various diseases, including childhood diarrhea [23, 24]. Predisposing factors considered for analysis were mothers/caregivers education as a dichotomous variable, age in three categories, ethnicity in five categories, religion as a dichotomous variable, marital status classified as married or currently not married, occupation as binary (housewife versus not a housewife), household size classified into two categories (2-5, 6 or more), age of under-five children was classified into five categories $(0-11,12-23,24-35,36-47$, and 48-59 months), number of under-five children in the house was categorized into two (1 child, 2 children or more), and birth order of under-five children was categorized into four (first, second, third, and fourth and above).

Enabling factors were monthly household income and availability of nearest health facilities within $15 \mathrm{~min}$ walking distance. Of the need factors (severity of illness), we included perceived cause of acute diarrhea, recognition of acute diarrhea danger signs, and number of danger signs (1, 2, 3 and 4 or more). Information was obtained from mothers/caregivers on the types of health facilities used and reasons for these choices. Weaning of food and liquid status during acute diarrheal illness and the types of treatment given at government and private health facilities were also studied.

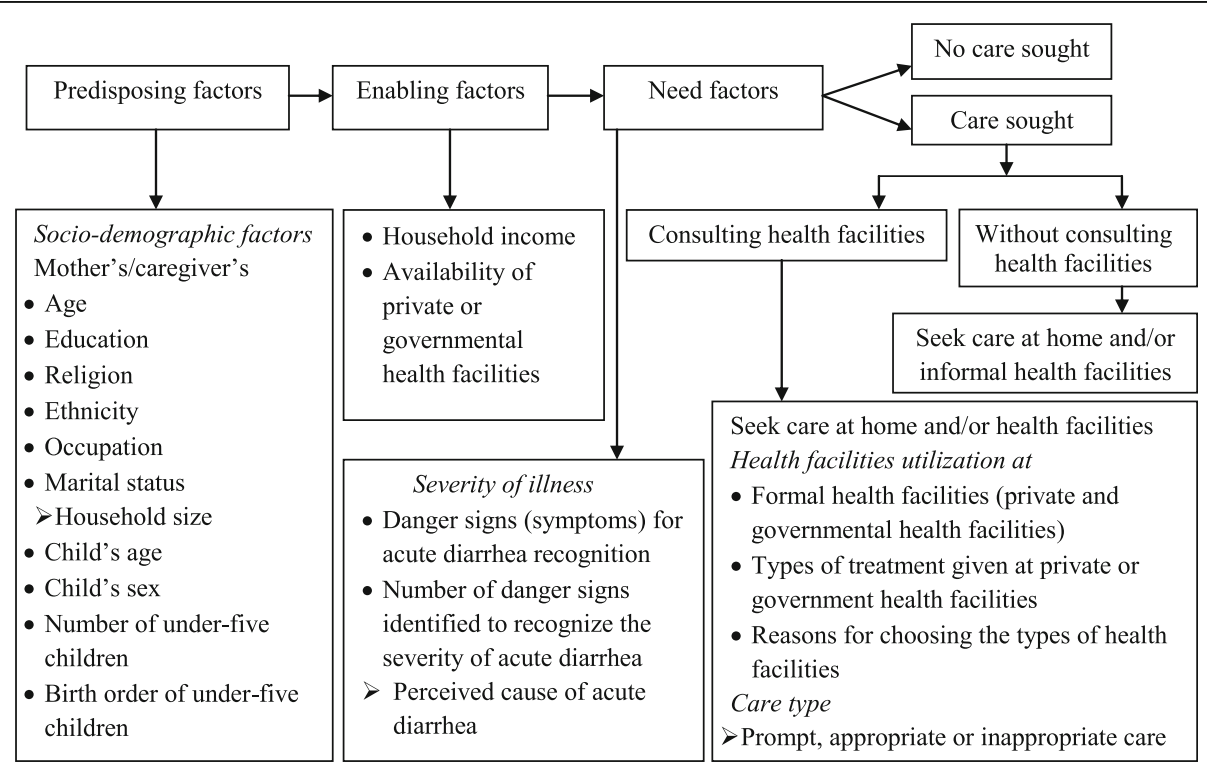

Fig. 1 Conceptual framework for health-seeking behavior modified from Andersen's behavioral model 


\section{Household survey, data quality control, and data management}

Data were collected using a pretested structured questionnaire. The content of the questionnaire covered predisposing, enabling, and need factors based on the adapted Andersen behavioral model conceptual framework (Fig. 1).

The questionnaire was prepared in English and translated into Amharic (local language). To maintain the consistency of the content, it was translated back into English and necessary adjustments were made before the translation back into Amharic for use in the field. The structured questionnaire was pretested in $10 \%$ of the sample size in one randomly selected slum kebele out of the studied kebeles and amended where necessary.

The principal investigator provided 2 days of training for seven field data enumerators and two supervisors about the administration of each question and ethical principles. The data collectors were female nurses and environmental health professionals with BSc degrees or diplomas, whereas the supervisors were public health professionals with masters of public health degrees. The primary respondents were the mothers of the under-five-year-old children who had acute diarrhea during the survey period. Where a mother was not a caregiver, another primary caregiver was interviewed. Ten percent of the study participants were randomly selected and re-interviewed by another interviewer to check reliability of the information entered by different interviewers. The completeness of the questionnaires was checked every day in the field by supervisors. The principal investigator then re-checked the questionnaires for consistency, clarity, and completeness. No substitution was made for mothers/caregivers who were either unavailable or unwilling to participate in the study. If a mother/caregiver was not available at the time of the survey, the data collectors scheduled another visit for the same or the next day. If not available again, the household was considered as non-respondent.

The collected data were computerized using EpiData Version 3.1 (EpiData Associations, Odense, Denmark) and then exported to Statistical Package for the Social Sciences (SPSS) Version 24.0 (IBM Corp., Armonk, N.Y., USA) for data cleaning. In order to verify the accuracy of data entries, two generic data verification strategies were employed. As the first step, randomly selected $10 \%$ of the questionnaires were thoroughly checked. Following this, descriptive statistics, results from cross-tabulations, and frequency distributions were examined before performing statistical analysis.

\section{Data analysis}

Data were analyzed using STATA Version 14.0 [25]. Proportions for categorical variables and mean $( \pm$ standard deviations (SD)) for continuous variables were used as descriptive measures. The associations between predisposing (block 1), enabling (block 2), and need (block 3 ) factors with health-seeking behavior were modeled using bivariate and multivariable logistic regression. Odds ratio with corresponding 95\% CI were used to assess the strength of associations of different factors with healthseeking behavior.

Bivariate analysis was employed to identify variables associated with health-seeking behavior without adjusting for potential confounding variables. To reduce excessive numbers of variables, only variables with $p<0.3$ in bivariate analysis were considered for initial inclusion in the multivariable analysis based on each block [26-28]. Variables with $p<0.3$ in each model (models 1,2 , and 3 ) of the multivariable analysis were included in the final model. Then, we estimated the overall effect of the three blocks of variables. Hosmer-Lemeshow statistics was used to test the goodness-of-fit of the model [29]. Variables with $p<0.05$ in the final model were taken as statistically significant and independently associated with health-seeking behavior.

\section{Results}

\section{Characteristics of the study participants}

A total of 452 mothers/caregivers who had under-fiveyear-old children with acute diarrhea were enrolled in the survey, with a response rate of $95.8 \%$. Nearly all respondents (98.9\%) were biological mothers. The mean household monthly income was 44.7( \pm 25.5$)$ United States Dollars (US\$). The mean household size was $5.2( \pm 1.9)$ persons, and the mean age of children was $27.2( \pm 14.2)$ months, the mean age of mothers/caregivers was $29.3( \pm 6.1)$ years, and $330(73.0 \%)$ of them were literate (Table 1).

\section{Health-seeking behavior}

More than two thirds 320 (70.8\%) of the mothers/caregivers sought care for their acute diarrheal under-fiveyear-old children either at home $(14.2 \%)$ or health facilities (56.6\%), and $29.2 \%$ of the mothers/caregivers reported that they did not seek any treatment either at home or in health facilities for the purpose of acute diarrhea treatment. Among mothers/caregivers who sought care, $87(27.2 \%)$ sought care promptly within $24 \mathrm{~h}$ after recognizing acute diarrhea and 39 (12.2\%) obtained inappropriate care. The mean walking time required by mothers/caregivers to reach the health facilities for seeking care was reportedly $28( \pm 14) \mathrm{min}$, and the mean number of elapsed days to get care after recognizing the danger sign of acute diarrhea was $2.3( \pm 1.5)$ days (Table 1$)$.

In bivariate analysis of predisposing factors, mothers/ caregivers literacy (crude odds ratio $(\mathrm{COR})=2.8 ; 95 \% \mathrm{CI}$ 1.8-4.4), married mother/caregiver $(\mathrm{COR}=1.7 ; 95 \% \mathrm{CI}$ 1.1-2.8), and occupation (not being a housewife) $(\mathrm{COR}=$ 1.6; $95 \%$ CI 1.1-2.6) were significantly associated with 
Table 1 Characteristics of mothers/caregivers of under-five children with acute diarrhea in slums of Addis Ababa, October 2014-July 2015

\begin{tabular}{|c|c|c|c|}
\hline Variables & n (\%) & Mean & SD \\
\hline \multicolumn{4}{|l|}{ Health-seeking behavior $(\mathrm{N}=452)$} \\
\hline Sought care & $320(70.8)$ & & \\
\hline No care sought for treating the child & $132(29.2)$ & & \\
\hline \multicolumn{4}{|l|}{ Where sought care given ( $N=452$ ) } \\
\hline $\begin{array}{l}\text { At home only without consulting } \\
\text { health facilities }\end{array}$ & $64(14.2)$ & & \\
\hline At health facilities & $256(56.6)$ & & \\
\hline Both at home and health facilities ${ }^{a}$ & $138(30.5)$ & & \\
\hline \multicolumn{4}{|l|}{ Care type $(N=320)$} \\
\hline Inappropriate care ${ }^{b}$ & $39(12.2)$ & & \\
\hline Prompt care ${ }^{c}$ & $87(27.2)$ & & \\
\hline Monthly household income (US\$) & & 44.7 & 25.5 \\
\hline Mothers/caregivers age (years) & & 29.3 & 6.1 \\
\hline \multicolumn{4}{|l|}{ Mothers/caregivers education ( $N=452)$} \\
\hline Illiterate & $122(27.0)$ & & \\
\hline Literate & $330(73.0)$ & & \\
\hline Household size $^{d}$ & & 5.2 & 1.9 \\
\hline Child's age (months) & & 27.2 & 14.2 \\
\hline $\begin{array}{l}\text { Time of walking to the nearest health } \\
\text { facility (minutes) }\end{array}$ & & 28 & 14 \\
\hline $\begin{array}{l}\text { Care sought after danger signs of acute } \\
\text { diarrhea (days) were recognized }\end{array}$ & & 2.3 & 1.5 \\
\hline
\end{tabular}

\section{N Denominator}

${ }^{a}$ Indicates sought care at health facilities and at home with consulting health facilities, it also included multiple response

${ }^{b}$ Care by giving medicine available at home without consulting health facilities, care from informal health facilities (traditional healers), or care from pharmacies or drug vendors

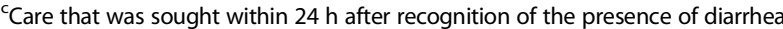

${ }^{\mathrm{d}}$ The number of persons living together in one house with one household head

health-seeking behavior (Table 2). Among enabling factors, having household monthly income of 50 US\$ and above, and availability of health facilities within $15 \mathrm{~min}$ walking distance were significantly associated with healthseeking behavior. From the need factors, recognizing danger signs of fever, thirst, vomiting, and increasing numbers of danger signs were significantly associated with healthseeking behavior (Table 3).

In multivariable analysis, predisposing factors of literacy of mothers/caregivers (adjusted odds ratio $(\mathrm{AOR})=2.4$; 95\% CI 1.4-4.1) and occupation of mothers/caregivers (not being a housewife) (AOR $=2.6$; 95\% CI 1.5-4.6) were significantly associated with health-seeking behavior. Among enabling factors, having household monthly income of 50 US $\$$ and above (AOR $=2.9 ; 95 \%$ CI 1.5-5.6) and availability of nearest health facilities within $15 \mathrm{~min}$ walking distance (AOR $=3.3$; 95\% CI 1.7-6.6) significantly increased the odds of health-seeking behavior. Of the need factors, fever (AOR $=4.3$; 95\% CI 2.4-7.6) and vomiting (AOR $=3.3 ; 95 \% \mathrm{CI} 1.8-5.9)$ as danger signs of severity of illness were significantly associated with health-seeking behavior (Table 4).

\section{Utilization of health facilities}

Among the 256 acute diarrheal under-five children taken to health facilities, 197 (76.9\%) were seen at government health facilities, $46(18.0 \%)$ at private health facilities, and $13(5.1 \%)$ by informal health facilities (traditional healers). Among mothers/caregivers who preferred government health facilities, most did so due to the lower treatment cost 173 (87.8\%). For those who preferred private health facilities, allegedly good quality of treatment was the main reason reported by 40 (86.9\%) (Table 5). Among mothers/ caregivers who sought treatment by consulting private and/or government health facilities, 182 (40.3\%) were given home-recommended fluids (HRF) and 180 (39.8\%) obtained oral rehydration salt (ORS). Only 54 (11.9\%) were given ORS plus zinc supplementation at health facilities (Table 6).

\section{Weaning practices}

One third 143 (33.8\%) of the acute diarrheal under-fiveyear-old children were given weaning food much less than normal. Somewhat reduced amounts of liquids were reportedly given by 120 (28.4\%) and greatly reduced amounts by $87(20.6 \%)$ mothers/caregivers either with or without consulting health facilities (Table 6).

\section{Discussion}

This community-based cross-sectional household study examined health facilities utilization and predictors of health-seeking behavior. Our main finding is that almost two thirds of under-five children with acute diarrhea sought care either at home or health facilities and one third did not receive any care. Out of those who sought care at health facilities, utilization of government health facilities was preferred by the majority, but prompt care within $24 \mathrm{~h}$ after recognizing acute diarrhea was low. Mothers/caregivers literacy, occupation, household monthly income, availability of health facilities within 15 min walking distance, and recognizing danger signs of fever and vomiting were significantly associated with healthseeking behavior.

Of the one third of mothers/caregivers who did not seek treatment for acute diarrhea reportedly gave weaning food and provided liquid for their children at home in different amounts compared to usual patterns. They did not seek care and continued weaning feedings, not with the intention of treating acute diarrhea. This might be due to mothers/caregivers expecting spontaneous recovery without treatment, lack of knowledge 
Table 2 Bivariate analysis of predisposing factors with health-seeking behavior in slums of Addis Ababa, October 2014-July 2015

\begin{tabular}{|c|c|c|c|}
\hline \multirow[t]{2}{*}{ Variables in block 1} & \multicolumn{2}{|c|}{ Health-seeking } & \multirow[t]{2}{*}{$\operatorname{COR}(95 \% \mathrm{Cl})$} \\
\hline & Sought care (\%) & No care sought (\%) & \\
\hline \multicolumn{4}{|c|}{ Mothers/caregivers age (years) } \\
\hline$<25$ & $60(70.6)$ & $25(29.4)$ & 1 \\
\hline $25-34$ & $196(73.1)$ & $72(26.9)$ & $1.1(0.7-1.9)$ \\
\hline$>34$ & $64(64.6)$ & $35(35.4)$ & $0.8(0.4-1.4)$ \\
\hline \multicolumn{4}{|c|}{ Mothers/caregivers education } \\
\hline Literate & $254(77.0)$ & $76(23.0)$ & $2.8(1.8-4.4)$ \\
\hline Illiterate & $66(54.1)$ & $56(45.9)$ & 1 \\
\hline \multicolumn{4}{|c|}{ Religion of mothers/caregivers } \\
\hline Christian & $288(70.4)$ & $121(29.6)$ & $0.8(0.4-1.7)$ \\
\hline Muslim & $32(74.4)$ & $11(25.6)$ & 1 \\
\hline \multicolumn{4}{|c|}{ Ethnicity of mothers/caregivers } \\
\hline Oromo & $74(73.3)$ & $27(26.7)$ & $1.1(0.6-2.0)$ \\
\hline Amhara & $106(69.7)$ & $46(30.3)$ & $0.9(0.5-1.6)$ \\
\hline Tigira & $31(70.5)$ & $13(29.5)$ & $0.9(0.4-2.1)$ \\
\hline Gurage & $40(67.8)$ & $19(32.2)$ & $0.8(0.4-1.7)$ \\
\hline Other ${ }^{\mathrm{a}}$ & 69 (71.9) & $27(28.1)$ & 1 \\
\hline \multicolumn{4}{|c|}{ Mothers/caregivers occupation } \\
\hline Not housewife & $66(62.9)$ & $39(37.1)$ & $1.6(1.1-2.6)$ \\
\hline Housewife & $254(73.2)$ & $93(26.8)$ & 1 \\
\hline \multicolumn{4}{|l|}{ Household size } \\
\hline $2-5$ persons & $196(68.3)$ & $91(31.7)$ & $0.7(0.5-1.1)$ \\
\hline 6 or more persons & $124(75.2)$ & $41(24.8)$ & 1 \\
\hline \multicolumn{4}{|c|}{ Marital status of mothers/caregivers } \\
\hline Married & $256(73.6)$ & $92(26.4)$ & $1.7(1.1-2.8)$ \\
\hline Currently not married & $64(61.5)$ & $40(38.5)$ & 1 \\
\hline \multicolumn{4}{|c|}{ Number of under-five children } \\
\hline 1 child & $231(69.6)$ & $101(30.4)$ & $0.8(0.5-1.3)$ \\
\hline 2 or more children & $89(74.2)$ & $31(25.8)$ & 1 \\
\hline \multicolumn{4}{|c|}{ Birth order of under-five children } \\
\hline First & $158(71.2)$ & $64(28.8)$ & $1.0(0.5-2.0)$ \\
\hline Second & $92(68.7)$ & $42(31.3)$ & $0.9(0.4-1.9)$ \\
\hline Third & $36(75.0)$ & $12(25.0)$ & $1.2(0.5-3.0)$ \\
\hline Fourth and above & $34(70.8)$ & $14(29.2)$ & 1 \\
\hline \multicolumn{4}{|l|}{ Child's age (months) } \\
\hline $0-11$ & $46(68.7)$ & $21(31.3)$ & 1 \\
\hline $12-23$ & $100(76.9)$ & $30(23.1)$ & $1.5(0.8-2.9)$ \\
\hline $24-35$ & $78(67.8)$ & $37(32.2)$ & $0.9(0.5-1.8)$ \\
\hline $36-47$ & $62(68.1)$ & 29 (31.9) & $0.9(0.5-1.9)$ \\
\hline $48-59$ & $34(69.4)$ & $15(30.6)$ & $1.0(0.5-2.3)$ \\
\hline \multicolumn{4}{|l|}{ Child's gender } \\
\hline Male & $151(67.4)$ & 73 (32.6) & $0.7(0.5-1.1)$ \\
\hline Female & 169 (74.1) & $59(25.9)$ & 1 \\
\hline
\end{tabular}


Table 3 Bivariate analysis of enabling and need factors with health-seeking behavior in slums of Addis Ababa, October 2014-July 2015

\begin{tabular}{|c|c|c|c|}
\hline \multirow[t]{2}{*}{ Variables in blocks 1 and 2} & \multicolumn{2}{|c|}{ Health-seeking } & \multirow[t]{2}{*}{ COR $(95 \% \mathrm{Cl})$} \\
\hline & $\begin{array}{l}\text { Sought } \\
\text { care (\%) }\end{array}$ & $\begin{array}{l}\text { No care } \\
\text { sought (\%) }\end{array}$ & \\
\hline \multicolumn{4}{|l|}{ Household monthly income } \\
\hline 50 US\$ and above & $105(87.5)$ & $15(12.5)$ & $3.8(2.2-6.8)$ \\
\hline Less than 50 US\$ $\$^{a}$ & $215(64.8)$ & $117(35.2)$ & 1 \\
\hline \multicolumn{4}{|c|}{ Estimated walking time to reach health facilities } \\
\hline Less than 15 min & $89(84.8)$ & $16(15.2)$ & $2.8(1.6-5.0)$ \\
\hline 15 min or more & $231(66.6)$ & $116(33.4)$ & 1 \\
\hline \multicolumn{4}{|l|}{ Recognized danger signs ${ }^{b}$} \\
\hline \multicolumn{4}{|c|}{ Three or more occurrences of watery/mucous stools in a day } \\
\hline Yes & $307(70.9)$ & $126(29.1)$ & $1.1(0.4-3.0)$ \\
\hline No & $13(68.4)$ & $6(31.6)$ & 1 \\
\hline \multicolumn{4}{|l|}{ Fever } \\
\hline Yes & $271(80.9)$ & $64(19.1)$ & $5.9(3.7-9.3)$ \\
\hline No & $49(41.9)$ & $68(58.1)$ & 1 \\
\hline \multicolumn{4}{|l|}{ Thirsty } \\
\hline Yes & $154(84.2)$ & $29(15.8)$ & $3.3(2.1-5.3)$ \\
\hline No & $166(61.7)$ & $103(38.3)$ & 1 \\
\hline \multicolumn{4}{|l|}{ Vomiting } \\
\hline Yes & $201(85.5)$ & $34(14.5)$ & $4.9(3.1-7.6)$ \\
\hline No & $119(54.8)$ & $98(45.2)$ & 1 \\
\hline \multicolumn{4}{|l|}{ Refused to eat/drink } \\
\hline Yes & $146(74.1)$ & $51(25.9)$ & $1.3(0.9-2.0)$ \\
\hline No & $174(68.2)$ & $81(31.8)$ & 1 \\
\hline \multicolumn{4}{|l|}{ Number of recognized danger signs } \\
\hline 1 & $35(41.2)$ & $50(58.8)$ & 1 \\
\hline 2 & $50(49.5)$ & $51(50.5)$ & $2.3(1.2-4.3)$ \\
\hline 3 & $51(73.9)$ & $18(26.1)$ & $4.0(2.0-8.1)$ \\
\hline 4 and above & $184(84.8)$ & $33(15.2)$ & $8.0(4.5-14.1)$ \\
\hline \multicolumn{4}{|l|}{ Perceived cause of acute diarrhea } \\
\hline Evil eye & $19(63.3)$ & $11(36.7)$ & 1 \\
\hline Teething & $51(73.9)$ & $18(26.1)$ & $1.1(0.4-3.4))$ \\
\hline Infection/weaning & $22(68.8)$ & $10(31.2)$ & $1.8(0.7-4.9)$ \\
\hline Drinking contaminated water & $46(78.0)$ & $13(22.0)$ & $1.4(0.5-4.3)$ \\
\hline Poor hygiene and sanitation & $168(70.3)$ & $71(29.7)$ & $2.3(0.8-6.4)$ \\
\hline $\begin{array}{l}\text { No knowledge about the } \\
\text { cause }\end{array}$ & $14(60.9)$ & $9(39.1)$ & $1.5(0.6-3.7)$ \\
\hline
\end{tabular}

1 Reference category

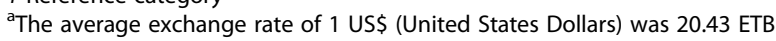
(Ethiopian birr) from October 2014-July 2015

${ }^{b}$ Danger signs mean the mothers/caregivers recognition of the severity of illness and the need for care about the severity of the illness, failure to recognize that the child was with diarrhea, or the common perception that diarrhea was due to new teething. Similar findings in two slums of Nairobi, Kenya, indicated that $35 \%$ of mothers/caregivers did not seek any care [30]. A study in Niger also revealed that one third of acute diarrheal under-five-year-old children were not taken to health facilities [31]. Another study, in Kolkata slums in India, reported that educated mothers/caregivers sought care at health facilities and home [32].

Low household income was a major deterrent to urban mothers/caregivers to seek prompt care in Western Nepal [24]. We also found that more than half $(56.6 \%)$ of mothers/caregivers sought care at health facilities, slightly below the rate reported by the 2016 Ethiopia Demographic Health Survey result for Addis Ababa [33]. Moreover, availability of health facilities within 15 min walking distance was a predictor for health-seeking behavior. Some studies pointed out that time needed to reach health facilities influences health-seeking behavior [34, 35]. An extensive study in Ethiopia reported that utilization of different types of government and private health facilities declined with distance from patient homes [36].

Severity of illness also increased seeking care in health facilities [23]. Our data also show that recognizing the severity of illness by danger signs of fever and vomiting increases the likelihood of seeking care, similar to other studies [24, 37]. Recognizing the danger signs and willingness to seek care tends to be associated with higher educational status and better household income. Contrary to our findings, some studies reported that perceived severity of illness was not a reliable predictor of care seeking by mothers/caregivers [38, 39]. However, an increasing body of empirical evidence indicates that children in low and middle income countries were more likely to receive care if their mothers/caregivers perceived illness to be serious $[24,37,40-46]$. We found that perceived cause of acute diarrhea was not a predictor for health-seeking, corroborating several other studies [24, 40, 43, 44].

Mothers/caregivers utilized government health facilities mainly due to low cost of treatment and private health facilities because of their allegedly higher quality of treatment. In contrast with our findings, Sreeramareddy et al. [23] in India reported that private health facilities were the first choice for treating childhood illnesses. Several studies found that high cost of treatment for childhood illnesses at health facilities were the most common deterrent to health facility utilization in rural and urban communities [47-49] and that service quality predicts choice of health facilities [50]. These results, as well as those from other studies, suggest that choice of utilization of health facilities depend on treatment cost and quality of health service. Promoting and supporting 
Table 4 Factors associated with health-seeking behavior in the multivariable logistic regression analysis

\begin{tabular}{|c|c|c|c|c|}
\hline \multirow[t]{2}{*}{ Variables } & Model I & Model II & Model III & Final model \\
\hline & AOR $(95 \% \mathrm{Cl})$ & AOR $(95 \% \mathrm{Cl})$ & AOR $(95 \% \mathrm{Cl})$ & AOR $(95 \% \mathrm{Cl})$ \\
\hline \multicolumn{5}{|l|}{ Mothers/caregivers education } \\
\hline Literate & $3.1(1.9-4.8)^{*}$ & & & $2.4(1.4-4.1)^{*}$ \\
\hline Illiterate & 1 & & & 1 \\
\hline \multicolumn{5}{|l|}{ Mothers/caregivers occupation } \\
\hline Not housewives & $1.7(1.1-2.8)^{*}$ & & & $2.6(1.5-4.6)^{*}$ \\
\hline Housewives & 1 & & & 1 \\
\hline \multicolumn{5}{|l|}{ Household size } \\
\hline $2-5$ persons & $0.8(0.5-1.2)$ & & & \\
\hline 6 or more persons & 1 & & & \\
\hline \multicolumn{5}{|l|}{ Child's age (months) } \\
\hline $0-11$ & 1 & & & 1 \\
\hline $12-23$ & $1.6(0.8-3.1)^{* *}$ & & & $1.5(0.7-3.4)$ \\
\hline $24-35$ & $0.9(0.5-1.8)$ & & & $0.8(0.3-1.7)$ \\
\hline $36-47$ & $0.9(0.4-1.8)$ & & & $0.6(0.3-1.5)$ \\
\hline $48-59$ & $1.2(0.5-2.6)$ & & & $0.7(0.3-1.9)$ \\
\hline \multicolumn{5}{|l|}{ Child's gender } \\
\hline Male & $0.8(0.5-1.5)$ & & & \\
\hline Female & 1 & & & \\
\hline \multicolumn{5}{|c|}{ Time of walking to the nearest health facility (minutes) } \\
\hline Less than $15 \mathrm{~min}$ & & $2.9(2.2-7.3)^{*}$ & & $3.3(1.7-6.6)^{*}$ \\
\hline 15 min or more & & 1 & & 1 \\
\hline \multicolumn{5}{|l|}{ Household monthly income } \\
\hline 50 US\$ and above & & $4.0(2.2-7.3)^{*}$ & & $2.9(1.5-5.6)^{*}$ \\
\hline Less than 50 US\$ & & 1 & & 1 \\
\hline \multicolumn{5}{|l|}{ Recognized danger signs } \\
\hline Thirsty & & & 1 & 1 \\
\hline Fever & & & $3.2(1.1-9.3)^{*}$ & $4.3(2.4-7.6)^{*}$ \\
\hline Vomiting & & & $2.9(1.2-6.8)^{*}$ & $3.3(1.8-5.9)^{*}$ \\
\hline Refused to eat/drink & & & $0.5(0.2-1.3)^{* *}$ & $0.7(0.4-1.2)$ \\
\hline \multicolumn{5}{|c|}{ Number of recognized danger signs } \\
\hline 1 & & & 1 & \\
\hline 2 & & & $1.1(0.4-3.4)$ & \\
\hline 3 & & & $1.3(0.2-7.7)$ & \\
\hline 4 and above & & & $1.5(0.1-18.7)$ & \\
\hline \multicolumn{5}{|l|}{ Perceived cause of acute diarrhea } \\
\hline Evil eye & & & 1 & 1 \\
\hline Teething & & & $1.2(0.3-4.2)$ & $1.1(0.3-4.2)$ \\
\hline Infection/weaning & & & $1.3(0.4-3.9)$ & $1.5(0.4-5.3)$ \\
\hline Drinking contaminated water & & & $1.2(0.3-4.0)$ & $1.2(0.3-4.6)$ \\
\hline Poor hygiene and sanitation & & & $2.4(0.7-7.5)^{* *}$ & $2.5(0.7-8.8)$ \\
\hline Do not know & & & $1.5(0.5-3.9)$ & $1.7(0.6-5.0)$ \\
\hline
\end{tabular}


Table 5 Health facilities utilization and reasons for seeking or not seeking care at health facilities in slums of Addis Ababa, October 2014-July 2015

\begin{tabular}{|c|c|c|c|}
\hline Variables & $\begin{array}{l}\text { Number } \\
(n)\end{array}$ & $\begin{array}{l}\text { Percentage } \\
(\%)\end{array}$ & $95 \% \mathrm{Cl}$ \\
\hline \multicolumn{4}{|c|}{ Reasons for not seeking care after recognizing acute diarrhea $(\mathrm{N}=132)^{a}$} \\
\hline Lack of money & 104 & 78.8 & $70.9-85.0$ \\
\hline $\begin{array}{l}\text { Long distance to the health } \\
\text { facilities }\end{array}$ & 25 & 18.9 & $13.1-26.6$ \\
\hline Illness was not serious & 90 & 68.2 & $59.6-75.6$ \\
\hline Mothers/caregivers was busy & 68 & 51.5 & $42.9-60.0$ \\
\hline High treatment cost & 24 & 18.2 & $12.4-25.8$ \\
\hline New teething & 9 & 6.8 & $3.5-12.7$ \\
\hline \multicolumn{4}{|c|}{ Types of health facilities used $(N=256)$} \\
\hline Government health facilities & 197 & 76.9 & 71.4-81.7 \\
\hline Private health facilities & 46 & 18.0 & $13.7-23.2$ \\
\hline Informal health facilities & 13 & 5.1 & $2.9-8.6$ \\
\hline \multicolumn{4}{|c|}{ Types of government health facilities $(N=197)$} \\
\hline Health center & 185 & 93.9 & $89.6-96.5$ \\
\hline Hospital & 12 & 6.1 & $3.4-10.4$ \\
\hline \multicolumn{4}{|c|}{ Types of private health facilities $(\mathrm{N}=46)$} \\
\hline Clinics $^{b}$ & 28 & 60.9 & $45.7-74.2$ \\
\hline Pharmacies or drug vendors & 12 & 26.1 & $15.1-41.1$ \\
\hline Hospital & 6 & 13.0 & $5.8-26.8$ \\
\hline \multicolumn{4}{|c|}{ Reasons for seeking care at government health facilities $(N=197)^{a}$} \\
\hline Low cost of treatment & 173 & 87.8 & $82.4-91.7$ \\
\hline Good treatment & 41 & 20.8 & $15.7-27.1$ \\
\hline Near to home & 120 & 60.9 & $53.8-67.5$ \\
\hline Illness was serious & 83 & 42.1 & $35.4-49.2$ \\
\hline $\begin{array}{l}\text { Treatment obtained within } \\
\text { a short period of time }\end{array}$ & 40 & 20.3 & $15.2-26.6$ \\
\hline \multicolumn{4}{|c|}{ Reasons for seeking care at private health facilities $(N=46)^{a}$} \\
\hline Good treatment & 40 & 86.9 & $73.2-94.2$ \\
\hline Near to home & 23 & 50.0 & $35.4-64.6$ \\
\hline Illness was serious & 31 & 67.4 & $52.1-79.7$ \\
\hline $\begin{array}{l}\text { Treatment obtained within } \\
\text { a short period of time }\end{array}$ & 16 & 34.8 & $22.1-50.0$ \\
\hline \multicolumn{4}{|c|}{ Reasons for seeking care at informal health facilities $(\mathrm{N}=13)^{\mathrm{a}}$} \\
\hline Low cost of treatment & 10 & 76.9 & $42.8-93.7$ \\
\hline Good treatment quality & 7 & 53.8 & $24.8-80.4$ \\
\hline Near to home & 8 & 61.5 & $30.5-85.3$ \\
\hline Illness was serious & 10 & 76.9 & $42.8-93.7$ \\
\hline $\begin{array}{l}\text { Treatment obtained within } \\
\text { a short period of time }\end{array}$ & 7 & 53.8 & $24.8-80.5$ \\
\hline
\end{tabular}

N Denominator

${ }^{a}$ There were multiple responses from the study participants

bLower, medium, and/or higher clinics
Table 6 Types of treatment given and feeding status for acute diarrheal under-five children in slums of Addis Ababa, October 2014-July 2015

\begin{tabular}{lcc}
\hline Variables & Number $(n)$ & Percentage (\%) \\
\hline $\begin{array}{l}\text { Treatment sought only by consulting } \\
\text { facilities }(\mathrm{N}=452)^{\text {a,b }}\end{array}$ & 180 & 39.8 \\
ORS & 182 & 40.3 \\
HRF & 54 & 11.9 \\
ORS plus zinc supplementation & 6 & 1.3 \\
Not any treatment given & 24 & 5.7 \\
Estimated amount of food given compared to normal $(\mathrm{N}=423)^{c}$ \\
More & 59 & 13.9 \\
Same as usual & 157 & 37.1 \\
Somewhat less & 143 & 33.8 \\
Much less & 27 & 6.4 \\
No food given & 13 & 3.1 \\
Do not know & 13 & 20.1 \\
Estimated amount of liquid given compared to normal $(\mathrm{N}=423)^{c}$ \\
More & 85 & 24.3 \\
Same as usual & 103 & 28.4 \\
Somewhat less & 120 & 20.6 \\
Much less & 87 & 3.5 \\
No liquid given & 15 & 3.1 \\
Do not know & &
\end{tabular}

N Denominator

${ }^{a}$ There were multiple responses from the study participants

${ }^{b}$ Did not include the treatment without consulting health facilities, which might lower the proportion of the treatment sought

Includes all mothers/caregivers who consulted health facilities to seek care and sought care without consulting health facilities and who did not intentionally provided weaning feeding/liquid to their children for treating acute diarrhea

public health centers improves access for low-income populations [51].

ORS plus zinc supplementation for acute diarrheal treatment was used relatively infrequently by our study population, whereas ORS and HRF were used by four times more of the mothers/caregivers than that of ORS plus zinc supplementation. The low use of ORS plus zinc supplementation in our study might be due to lack of advocacy by government health offices, health extension workers, non-governmental organizations, and civic societies who are interested in promoting ORS plus zinc supplementations. The utilization rates of ORS is slightly lower than the aggregated data of the 2011 Demographic Health Survey report of fluid from ORS packets (43.4\%) [17] and lower than the 2016 Demographic Health Survey report of fluid from ORS packets (55.8\%) in Addis Ababa [33]. This indicates inequitable use of ORS between the whole Addis Ababa and the slums of Addis Ababa, which might be due to lower socioeconomic status of slum residents and lack of proximity of health facilities for slum mothers/ 
caregivers. In contrary with our findings, a similar study in Niger by Page et al. [31] found that ORS was used by almost three fourth of mothers/caregivers for treating diarrhea.

\section{Strength and limitations}

By adapting predisposing, enabling, and need factors of Andersen behavioral model, we were able to identify the most important predictors for health-seeking behavior for acute diarrheal under-five children in slums of Addis Ababa. As a limitation, our conceptual framework did not consider quality of care sought and several community level variables which might play a role in determining care seeking. Addressing disparities in health access should ensure that everyone has access to high-quality care [52]. Our data analysis did not consider utilization of health facilities as an outcome variable. Instead, we used healthseeking behavior as an outcome. However, we analyzed descriptive statistics for different types of health facilities utilized and underlying reasons for the choices, which explain the health-seeking behavior in health facilities.

\section{Conclusions}

Our findings show health facilities becoming a better choice to seek care than seeking care at home. The results suggest that upgrading of slums as part of urban development, particularly infrastructure development including the construction of health facilities within slums, and raising the socioeconomic level of the slum populations can increase access to care for mothers/caregivers with acute diarrheal under-five children. Rates of prompt and effective treatment, both at home and health facilities, may be further increased by health promotion programs targeting illiterate mothers/caregivers and poor households. The Urban Safety Net Program, enacted by the Ministry of Urban Development and Housing of Ethiopia in January 2017, is seeking to raise the socioeconomic status and livelihoods of poor residents in Addis Ababa and may thus foster conditions necessary for successful interventions, and the impact of this program for increasing health-seeking behavior and health facilities utilization should be studied. Further studies that integrate household, community, and health facility information pertaining to predisposing, enabling, and need factors at the household, health facility, and community levels may provide comprehensive assessments of opportunities and constraints in promoting health-seeking and health facility utilization for treating acute diarrheal under-five children in Addis Ababa slums.

\section{Abbreviations}

AOR: Adjusted odds ratio; Cl: Confidence interval; COR: Crude odds ratio; HRF: Home-recommended fluids; ORS: Oral rehydration salt; SD: Standard deviations; US\$: United States Dollars; WHO: World Health Organization

\section{Acknowledgements}

We thank the Ethiopian Institute of Water Resources of Addis Ababa University and Wollo University for funding the research. We also acknowledge the support of Linda A. Willis, Shirley Lewis and Adrienne Cruise for their financial assistance. We also thank Addis Ababa City Health Administration Bureau, Gullele Sub-City District 01 and Lideta Sub-City District 05 health offices for their cooperation during the data collection. Our special thanks go to the mothers/ caregivers of under-five children with acute diarrhea for their dedication and commitment in providing information.

\section{Funding}

The research was funded by Ethiopian Institute of Water Resources of Addis Ababa University and Wollo University. The funders had no responsibility in the study design, data collection, data analysis, interpretation of the data, and preparation of the manuscript for publication.

\section{Availability of data and materials}

The datasets used and/or analyzed during the current study are available from the corresponding author on reasonable request.

\section{Authors' contributions}

MA was involved in the proposal development, data collection, data management, analysis, and write-up of the article. BM, GM, HK, and WM were involved in the proposal development, data analysis, and writing and editing the manuscript. MA, BM, GM, HK, and WM developed the survey tool. All authors have read and approved the final manuscript.

\section{Competing interests}

The authors declare that they have no competing interests.

\section{Consent for publication}

Not applicable.

\section{Ethics approval and consent to participate}

This study adhered to the principles that govern medical research involving human subjects specified by the Council for International Organizations of Medical Sciences [53]. Data collection tools, participant information sheet, and the consent forms were reviewed by the Institutional Ethical Review Committee of Wollo University, College of Medicine and Health Sciences prior to the issuance of ethical approval letter. During the survey, interviewers informed mothers/caregivers that participation in the study was voluntary. Participants were also assured about the confidentiality of the information provided and that they could decline to answer any of the questions during the interview and opt out of the study. Study participants were also informed that information sought was not used for any other purpose than what participants consented to and was not being passed on to a third party. Written informed consent/assent was obtained from each study child's mother or caregiver.

\section{Publisher's Note}

Springer Nature remains neutral with regard to jurisdictional claims in published maps and institutional affiliations.

\section{Author details}

${ }^{1}$ Ethiopian Institute of Water Resources (EIWR), Addis Ababa University, Addis Ababa, Ethiopia. ${ }^{2}$ College of Health and Medical Sciences, Haramaya University, Haramaya, Ethiopia. ${ }^{3}$ Department of Civil and Environmental Engineering, University of Connecticut, Storrs, USA. ${ }^{4}$ Department of Epidemiology and Biostatistics, University of California, San Francisco, USA. ${ }^{5}$ Aklilu Lemma Institute of Pathobiology, Addis Ababa University, Addis Ababa, Ethiopia.

Received: 24 November 2016 Accepted: 6 March 2017 Published online: 04 April 2017

\section{References}

1. Wardlaw T, Salama P, Brocklehurst C, Chopra M, Mason E. Diarrhoea: why children are still dying and what can be done. Lancet. 2010;375(9718):870-2.

2. UNICEF and WHO. Diarrhoea: why children are still dying and what can be done. World Health Organization. Geneva: WHO and UNICEF; 2009. p. 1-68. 
3. Podewils L, Mintz E, Nataro J, Arashar U. Acute infectious diarrhoea among children in developing countries. Semin Pediatr Infect Dis. 2004;15(3):155-68.

4. Pelto P, Pelto G. Developing applied medical anthropology in third world countries: problems and actions. Soc Sci Med. 1992;35(11):1389-95.

5. WHO and UNICEF. Counsel the mother: integrated management of childhood illnesses (IMCI). Divsion of child health and development. IMCI guidelines. Geneva: WHO and UNICEF; 2012.

6. Claeson M, Waldman RJ. The evolution of child health programmes in developing countries: from targeting diseases to targeting people. Bull World Health Organ. 2000;78(10):1234-45.

7. Andersen R. A behavioral model of families' use of health services. Chicago: Center for health administration studies, University of Chicago. Research Ser; 1968. p. 25.

8. Andersen R, Newman JF. Societal and individual determinants of medical care utilization in the United States. Milbank Mem Fund Q Health Soc. 1973; 51(1):95-124.

9. Andersen R, Rice T, Kominski G. Changing the US health care system: Key issues in health services, policy, and management. $2^{\text {nd }}$ ed. San Francisco: Jossey-Bass; 2001.

10. Azage M, Kumie A, Worku A, Bagtzoglou AC. Childhood diarrhea in high and low hotspot districts of Amhara Region, Northwest Ethiopia: a multilevel modeling. J Health Popul Nutr. 2016;35(13). doi:10.1186/s41043-016-0052-2.

11. Babitsch B, Gohl D, Von LT. Re-revisiting Andersen's behavioral model of health services use: A systematic review of studies from 1998-2011. GMS Psychosoc Med. 2012;9. doi:10.3205/psm000089.

12. Ghosh R. Child mortality in India: A complex situation. World J Pediatr. 2012;8(1):11-8

13. Srivastava NM, Awasthi S, Agarwal GG. Care seeking behavior and out-ofpocket expenditure for sick newborns among urban poor in Lucknow, Northern India: A prospective follow up study. BMC Health Serv Res. 2009;9(61). doi:10.1186/1472-6963-9-61.

14. Thind A. Health service use by children in rural Bihar. J Trop Pediatr. 2004; 50(3):137-42.

15. Fosu GB. Childhood morbidity and health services utilization: cross-national comparisons of user-related factors from DHS data. Soc Sci Med. 1994; 38(9):1209-20

16. Chowdhury ME, Ronsmans C, Killewo J, Anwar I, Gausia K, Das-Gupta S, et al. Equity in use of home-based or facility-based skilled obstetric care in rural Bangladesh: an observational study. Lancet. 2006:367(9507):327-32.

17. Ethiopia Demographic and Health Survey: Ethiopia Demographic and Health Survey 2011. Addis Ababa, Ethiopia, and Calverton, Maryland, USA. Central Statistical Agency [Ethiopia] and ORC Macro; 2012.

18. Central Statistical Agency. Population projection of Ethiopia for all regions, at woreda level from 2014-2017. Addis Ababa: Central Statistical Agency (CSA); 2013.

19. Federal Ministry of Health of Ethiopia. National strategy for child survival in Ethiopia. Addis Ababa: Family Health Department, Ministry of Health; 2005.

20. Kelsey J, Whittemore A, Evans A, Thompson W. Methods of sampling and estimation of sample size. Methods in observational epidemiology. New York: Oxford University Press; 1996.

21. World Health Organization. The treatment of diarrhea. A manual for physicians and other senior health workers. Geneva: World Health Organization; 2005.

22. Farthing $M$, Salam M, Lindberg G, Dite $P$, Khalit I, Lindo-Salazar E, et al. World Gastroenterology Organization Global Guidelines. Acute diarrhea in adults and children: a global perspective. World Gastroenterology Organization. 2012;1-24. http://www.worldgastroenterology.org/UserFiles/ file/guidelines/acute-diarrhea-english-2012.pdf. Accessed 10 May 2014

23. Sreeramareddy C, Sathyanarayana T, Kumar H. Utilization of health care services for childhood morbidity and associated factors in India: a national cross-sectional household survey. PLoS One. 2012;7(12):e51904.

24. Sreeramareddy CT, Shankar RP, Sreekumaran BV, Subba SH, Joshi HS, Ramachandran U. Care seeking behaviour for childhood illness-a questionnaire survey in western Nepal. BMC Int Health Hum Rights. 2006;6(7). doi:10.1186/1472-698X-6-7.

25. StataCorp. Statistical software. College station: StataCorp LP; 2015. Release 14

26. Kirkwood BR, Sterne JA. Medical statistics: chapter 29: regression modelling In: Kirkwood BR, Sterne JAC, editors. Essential medical statistics. $2^{\text {nd }}$ ed. Hoboken: Blackwell Science; 2003.
27. McNamee R. Confounding and confounders. Occup Environ Med. 2003;60(3):227-34

28. Bursac Z, Gauss CH, Williams DK, Hosmer DW. Purposeful selection of variables in logistic regression. Source Code Biol Med. 2008;3(17). doi:10.1186/1751-0473-3-17.

29. Hosmer J, David W, Lemeshow S, Sturdivant RX. Applied logistic regression. $3^{\text {rd }}$ ed. Hoboken: Johns Wiley and Sons; 2013.

30. Mukiira C, Ibisomi L. Health care seeking practices of caregivers of children under-five with diarrhea in two informal settlements in Nairobi, Kenya. J Child Health Care. 2013;19(2):254-64.

31. Page AL, Hustache S, Luquero FJ, Djibo A, Manzo ML, Grais RF. Health care seeking behavior for diarrhoea in children under-five in rural Niger: Results of a cross-sectional survey. BMC Public Health. 2011;11(389). doi:10.1186/ 1471-2458-11-389.

32. Manna B, Nasrin D, Kanungo S, Roy S, Ramamurthy T, Kotloff KL, et al. Determinants of health care seeking for diarrhoeal illness in young children in urban slums of Kolkata, India. Am J Trop Med Hyg. 2013;89(Suppl 1):56-61.

33. Ethiopia Demographic and Health Survey. Ethiopia Demographic and Health Survey 2016: key indicators report. Addis Ababa: Central Statistical Agency (CSA) [Ethiopia] and ICF; 2016.

34. NoorAli R, Luby S, Rahbar M. Does use of a government service depend on distance from the health facility? Health Policy Plan. 1999;14(2):191-7.

35. Okwaraji YB, Cousens S, Berhane Y, Mulholland K, Edmond K. Effect of geographical access to health facilities on child mortality in rural Ethiopia: a community based cross-sectional study. PLoS One. 2012;7(3):e33564.

36. Kloos H. Utilization of selected hospitals, health centres and health stations in central, southern and western Ethiopia. Soc Sci Med. 1990;31(2):101-14.

37. Taffa N, Chepngeno G. Determinants of health care seeking for childhood illnesses in Nairobi slums. Trop Med Int Health. 2005;10(3):240-5.

38. Herman E, Black RE, Wahba S, Khallaf N. Developing strategies to encourage appropriate care-seeking for children with acute respiratory infections: an example from Egypt. Int J Health Plann Manage. 1994;9(3):235-43.

39. Hill Z, Kendall C, Arthur P, Kirkwood B, Adjei E. Recognizing childhood illnesses and their traditional explanations: exploring options for careseeking interventions in the context of the $\mathrm{IMCl}$ strategy in rural Ghana. Trop Med Int Health. 2003;8(7):668-76.

40. Yoder PS, Hornik RC. Perceptions of severity of diarrhoea and treatment choice: a comparative study of HealthCom sites. J Trop Med Hyg. 1994:97(1):1-12

41. Goldman N, Heuveline P. Health-seeking behaviour for child illness in Guatemala. Trop Med Int Health. 2000;5(2):145-55.

42. Goldman N, Pebley A, Gragnolati M. Choices about treatment for ARI and diarrhea in rural Guatemala. Soc Sci Med. 2002:55(10):1693-712.

43. Pillai RK, Williams SV, Glick HA, Polsky D, Berlin JA, Lowe RA. Factors affecting decisions to seek treatment for sick children in Kerala, India. Soc Sci Med. 2003;57(5):783-90.

44. Thind A. Analysis of health services use for respiratory illness in Indonesian children: implications for policy. J Bioso Sci. 2005;37(2):129-42.

45. De-Silva M, Wijekoon A, Hornik R, Martines J. Care seeking in Sri Lanka: one possible explanation for low child mortality. Soc Sci Med. 2001;53(10):1363-72.

46. Gelaw YA, Gashaw AB, Kefyalew A. Effect of residence on mothers' health care seeking behavior for common childhood illness in Northwest Ethiopia: a community based comparative cross-sectional study. BMC Res Notes. 2014;7(705). doi:10.1186/1756-0500-7-705

47. Tarimo D, Lwihula G, Minjas J, Bygbjerg I. Mothers' perceptions and knowledge on childhood malaria in the holo-endemic Kibaha district, Tanzania: implications for malaria control and the integrated managemnet of childhood illnesss (IMCl) strategy. Trop Med Int Health. 2000:5(3):179-84.

48. Thind A, Andersen R. Respiratory illness in the Dominican Republic: what are the predictors for health services utilization of young children? Soc Sci Med. 2003:56(6):1173-82.

49. Thind A, Cruz A. Determinants of children's health service utilization in the Philippines. J Trop Pediatr. 2003;49(5):269-73.

50. Andaleeb SS. Public and private hospitals in Bangladesh: service quality and predictors of hospital choice. Health Policy Plan. 2000;15(1):95-102. 
51. Andersen RM, Yu H, Wyn R, Davidson PL, Brown ER, Teleki S. Access to medical care for low-income persons: how do communities make a difference? Med Care Res Rev. 2002;59(4):384-411.

52. Derose KP, Gresenz CR, Ringel JS. Understanding disparities in health care access and reducing them through a focus on public health. Health Aff. 2011;30(10):1844-51.

53. Council for International Organizations of Medical Sciences. International ethical guidelines for biomedical research involving human subjects. Bull Med Ethics. 2002;182:17-23. PMID:14983848.

Submit your next manuscript to BioMed Central and we will help you at every step:

- We accept pre-submission inquiries

- Our selector tool helps you to find the most relevant journal

- We provide round the clock customer support

- Convenient online submission

- Thorough peer review

- Inclusion in PubMed and all major indexing services

- Maximum visibility for your research

Submit your manuscript at www.biomedcentral.com/submit 